\title{
Patients, pharmacists, and the placebo in France: From iatrogenic to ethical risks
}

\section{Sylvie Fainzang}

INSERM, France

sylvie.fainzang@orange.fr

Fainzang, S. (2015). Patients, pharmacists and the placebo in France: From iatrogenic to ethical risks, Tidsskrift for Forskning i Sygdom og Samfund, nr. 23, 89-109.

Placebos have attracted widespread interest amongst anthropologists who have sought to explain the placebo dimension of medicines or healing rituals prescribed by health professionals or traditional healers by emphasizing aspects relating to symbolic healing. Very little investigation has been done however into the perceptions individuals hold of placebos, and their reasons for resorting to placebos and/or the placebo effect within the framework of family medication, on one hand, and the perception pharmacists have on this issue and the uses they make of it in their responses to the demands of users, on the other. This article addresses their uses of placebos and the placebo effect within the context of medicinal risk management in France; it also examines the perception actors have of placebos (whether 'pure' or 'impure') in the light of their ethical positions.

\section{Introduction}

Scholars from numerous disciplines have taken an interest in placebos and have proposed diverse approaches: historical, epistemological, physiological, neurological or psychological (Benedetti et al., 2005; Benedetti et al., 2011 ; Jensen et al., 
2014; Mayberg et al., 2002). The notion of the placebo is used in two very different contexts: in research practice and in routine care. When the use of placebos is examined, it is generally done either to show the position they occupy in trials of new medicines and to determine their effect - what Boussageon (2008) calls the 'dark side' of the controlled clinical trial - or to show that they are used by practitioners within the framework of their clinical activity.

Anthropology in turn, has been particularly interested in the 'placebo effect'1. The discipline has demonstrated the placebo dimension of treatments prescribed by health professionals or traditional health practitioners beyond the constituent elements of these treatments. In emphasizing aspects relative to symbolic healing, anthropological studies have in particular underlined the placebo effect of therapeutic rituals (Peters, 2001; Ostenfeld, 2012), shown the existence of cultural variations in the placebo effect (Moerman, 2000; Helman, 2001), demonstrated that the interpretation of the placebo effect depends on the context (Thompson, Ritenbaugh \& Nichter, 2009), and have related their thinking on the subject to the question of belief (Cathebras, 2008) - to such a degree in fact that in biomedicine the term the 'placebo effect' is often used to encompass everything related to symbolic healing, as Whyte, Van der Geest \& Hardon (2002) have noted.

Although many studies have focused on the use of placebos in clinical practice, very little investigation has been done on the perceptions individuals hold of placebos and their reasons for resorting to placebos and/or the placebo effect within the framework of family medication, on one hand, and the perceptions and uses of pharmacists in response to the demands of clients, on the other.

This is what I propose to examine in this article in the context of France. Indeed, nowadays placebos not only play an important role in medical practice, they also constitute part of the work in officinal practice - although there is no consensus as to the ethical or unethical nature of selling a placebo to a patient seeking medical treatment. The article will describe this informal practice, and people's thoughts about the values and the risks of administering placebos, whether this is done by consulting a pharmacist or within the framework of family medication. My aim in analysing these representations and practices is to contribute to anthropological reflection on the social uses in this field.

My reflection will cover the uses placebos are put to, which we will see are generally positioned within the context of the management of the risk associated with medicines, and the perception actors have of placebos in the light of their ethical positions. Therefore, I am not looking here to define what makes the placebo effective or what creates the placebo effect ${ }^{2}$, but the perceptions and social uses 
of placebos by the very people who know the treatment is a placebo or a medicine from which they expect a placebo effect. Evidently, people cannot discuss their use of placebos on themselves since, to have an effect, the placebo has to be viewed as real medicine. So, they are not talking about their own use of placebos (except in retrospect), but of situations where they know they are using a placebo while the intended recipient does not. In other words, it is a case of defining what determines recourse to a placebo as an object likely to produce an effect even though it is perceived as a substance devoid of intrinsic efficacy - a recourse that takes place either in secret at home, or in collaboration with a pharmacist.

This reflection is based on materials gathered during three studies carried out in France. The first examined patient behaviour regarding medicines and prescriptions. It was carried out in the south of France and involved 186 patients living in both urban and rural areas, from different religious and cultural backgrounds, and belonging to very diverse socio-professional categories (Fainzang, 2001, 2005). The second study focused on self-medication. It explored the different problems for which the respondents had sought treatment for themselves or for their family, the conditions under which they chose either to consult a doctor or to treat themselves, the resources they used to identify the problem and to select the appropriate treatment, the strategies they adopted to ensure a satisfactory riskbenefit ratio, etc. It was carried out in Paris and involved forty people, belonging to the different social milieus that can be included in the term the "middle classes" which nowadays covers the intermediate classes and part of what used to be the working and upper classes (Fainzang, 2012, 2013). The third one, still in progress, addresses lay management of medicinal risks. It is also being carried out in the Paris region, with people belonging to the "middle classes" (Fainzang, 2014).

All three research projects involved people of both sexes and from various socio-professional backgrounds. The people studied were met on several occasions, in order to understand (through their gestures, words and actions) their systems of thought. Some were met through the "snowball" method, others through the intermediary of health professionals. The research was mostly carried out at people's homes, and thus consisted for a large part of interviews - even if, in some cases, the interviews were combined with in situ observation concerning the choices people made when experiencing or dealing with a symptom. Moreover, I collected information from the informants on the conditions in which the drugs detained in their household medicine cabinets were acquired and used. The material collected also resulted from observations of consultations, and from interviews with pharmacists throughout the research processes. 
Thus, the material on which this article is based was gathered within a research framework where the main subject was not the placebo but medicinal use; however, the issue of placebos was addressed during these interviews. This paper focuses on patients' and pharmacists' discourses and practices with regard to placebos in the context of their behaviour regarding their perception of pharmaceutical risks. With the added perspective of data provided by literature on the prescription of placebos by doctors, I will present here information on the use of placebos by people themselves, and the role played by pharmacists in response to demand from clients, along with their practices and their ethical postures. Contrasting attitudes exist among both patients and pharmacists: fears, hesitancies and categorical refusals, but also hopes, passions and even ambivalent feelings. These attitudes cross over and converge with both the therapeutic and ethical options. We will see in particular that while individual practices depend on heterogeneous philosophical and pragmatic positions, acceptance (or refusal) of the use of placebos is often the result of a compromise between the desire to avoid taking a risk in the therapeutic register and a desire to avoid doing so in the ethical one.

\section{Placebos in medical prescriptions}

In clinical practice today, it is established that the placebo effect is much larger than is traditionally thought, since it also exists for verum, and that the placebo effect should not be perceived as a pollutant (Cathebras, 2006) but as a fundamental ingredient in therapeutic efficacy. This phenomenon has led to a distinction in the medical milieu between 'pure' and 'impure' placebos. The 'pure' placebo, which is totally devoid of pharmacodynamic action, is created by inert substances with no physiological nor pharmacological effect. The 'impure' placebo is a medicine with no proven pharmacological activity in the situation in which it is employed, or an efficacious medicine used for other indications, in other words, it is prescribed in a situation where this efficacy has not been demonstrated, and where the relationship the patient has formed between the molecule and his/her affliction is due to a placebo mechanism (Spiro 1986).

The literature on the subject shows such prescriptions. Using a large study carried out in the UK, Howick et al. (2013) show that many doctors reported having prescribed placebos in their careers, by concealing from the patients that the prescribed substance had no active ingredients ${ }^{3}$. Equally, a study on the prescription of placebos in the United States (Tilburt J. et al, 2008) showed that almost one in 
two doctors (46\%) regularly prescribe placebos several times a month. $2 \%$ of the placebos prescribed are sugar pills, $3 \%$ saline solutions, and only $5 \%$ of doctors discuss the issue of placebos with their patients.

In France too, doctors sometimes resort to prescribing placebos to their patients although, here too, they are often 'impure' placebos. The Vidal Drug Compendium (a French medical work that brings together summaries of the characteristics of products from pharmaceutical laboratories) is known to contain nearly $50 \%$ of so-called 'impure' placebos (Spiro 1986). The frequency of such prescription is difficult to establish. According to P. Maire (2008), while impure placebos are still prescribed today in non-hospital medicine, pure placebos are rarely prescribed as such, contrarily to circumstances twenty years ago in hospitals, a difference he attributes to the increased ethical awareness recently expressed in charters of patients' rights. It is difficult to ascertain real figures for placebo prescriptions since doctors often deny such use, or only discuss it amongst colleagues. Hofling (1955) had already noted that the majority of practitioners were convinced they resorted to the prescription and use of placebos less often than their colleagues. And numerous doctors today still mention the topic to say that other doctors use them, but they do not.

Doctors generally justify such prescriptions when presented with symptoms they judge not particularly serious or those they diagnose as functional or psychological, or when they have no other therapeutic solution or they believe that a genuine analgesic is not appropriate for the patient since it could provoke adverse side-effects. But a medicine can be genuine (with marketing authorisation and an indication conforming to the context in which it is prescribed) but nevertheless considered as a placebo by the doctor. Thus, Dr C, a rheumatologist, regularly prescribes anti-arthritics even though he says that no study has yet proven their efficacy. He considers them to be placebos and prescribes them so that they act as placebos on the patients. As we can see, the distinction between 'pure' and 'impure' is not sufficient to account for all the uses of placebos in clinical practice since the situation proves to be much more complex.

The anthropological literature nevertheless demonstrates the persistence of such uses. Observations led by Anne Vega (2011) show that some doctors, amongst those she calls the 'little prescribers', replace sleeping pills with placebos and progressively un-prescribe the psychoactive drugs that their new patients are taking, with the aim of reducing their medicinal consumption. Moreover, some doctors publicly declare their use of this type of prescription when they judge a medicinal prescription to be useless. The president of the French National Syndicate of 
Young GPs thus told the Express newspaper: 'It can happen that we prescribe placebos [...]. Some patients find leaving the doctor's cabinet without a prescription difficult to understand.' (The Express, 2012).

Prescriptions of placebos are mainly given for pain and insomnia, even if, according to Beecher (1955), all pathologies are susceptible to the placebo effect. Actually, the extent of the placebo effect is a subject of controversy. In contrast to Beecher, Jean-Jacques Aulas (2008) believes that the placebo effect does not apply to all pathologies and that it only works on pathologies with a strongly subjective component, in particular on pain, anxiety, sleeping problems, moderate depression and psychofunctional complaints, which make up a large part of the reasons for consulting a GP; whereas, for his part, Zigmond (1984) notes that it is well established that placebos can have a positive therapeutic effect in a very wide range of disease processes in any bodily system.

\section{Placebos in family medication}

The placebo effect is often attributed to the 'doctor effect' (Moreau, 2008 ; Brody, 1997), or to what Pignarre (2008) refers to as the 'white coat effect' (p. 91), particularly since Michael Balint (1957) famously wrote that the most frequently used drug in general medicine is the doctor him/herself (p. 9). In this regard the quality of the therapeutic relationship between clinician and patient has also been discussed (Thompson, Ritenbaugh \& Nichter, 2009), as well as 'trust' in the prescribing doctor, which everyone agrees is a prerequisite for the placebo effect to work. In the literature, the use of placebos for therapeutic ends is in fact always discussed within the framework of clinical practice. Thus, when Thompson, Ritenbaugh \& Nichter (2009) describe the domains in which the placebo is used, they only mention clinical research and clinical practice. Equally, Thalabard (2008) believes that the placebo can only be used when the decision comes from the doctor.

However, there exists a social configuration that is never explored, where individuals choose to resort to a placebo for a family member within the framework of family medication. The placebo effect itself, which is generally portrayed as the result of an interaction between doctor and patient, can also occur when a product is administered outside of medical prescriptions. It is these domestic uses that are of interest here, and I will attempt to understand their mechanisms of use and the logics that underpin them. 
Indeed, some lay uses of the placebo can be observed, meaning the initiative of people who give or advise placebos, or medicines they hope will have a placebo effect, to members of their family. It can be a case of a person (generally a woman) doing so for her spouse or elderly parent, or of a parent (most often the mother) for her child. These uses are, for a large part, in line with the logics and the concerns behind doctors' prescriptions. The person is trying to avoid giving a real pharmaceutical to a family member when he/she thinks that this is not necessary or that the symptom is not serious, when the aim is to avoid a pointless consumption of medicines. Or the person gives a different medicine from that with the corresponding indications for the affliction in question when that allows the risks involved in administering the correctly indicated drug to be avoided. In all these cases, family use of a placebo aims to mitigate the risks associated with consuming certain medicines.

Thus, we can see that placebos are employed within the family, as the following examples show. Mrs G, whose 10-year-old daughter had a cough, had asked her doctor to prescribe a cough medicine, but he had advised her not to use such medicines and suggested she confine herself to using the pharyngitis treatment he had given her previously. Instead she made a pure placebo using grenadine cordial with added sugar and a small amount of flour to thicken it. Mrs A, for her part, gives her son paracetamol when he complains of problems getting to sleep. She refuses to give him a tranquilizer since she is against the use of psychoactive drugs, 'especially for children', she explained. Even though she considers paracetamol to be a real medicine, she does not believe it has any tranquilizing properties, but she uses it in the hope it will have a placebo effect on her son; 'at least, there is no risk', she explained ${ }^{4}$. The aim is to avoid using a medicine considered risky and to substitute it for another thought to be devoid of harmful effects while making the person being treated believe that it has the same properties. Here, she uses an 'impure placebo' as it carries an active principle but for a different indication. Yet, the notion of an 'impure placebo' is relatively unknown to the public. It is an etic definition, recognized by the specialists working on this issue within the framework of clinical practice. At the emic level, people speak of 'placebos' to refer to the use of substances from which they expect a placebo effect, whether these are authentic medicines or not.

Use of a pharmaceutical can be accidental and its effect can sometimes be discovered by chance during or after a treatment. Mrs B. explained she had 'miscast' a medicine (to mean there was no link with the use for which it is indicated), having confused two medicines with similar names. This type of mistake can happen 
when there is a similarity between the boxes, the pills themselves or the commercial names of different proprietary drugs. One evening, she was suffering from insomnia which she wanted to tackle by taking a soporific drug, but instead she took a medicine indicated for digestive problems, which turned out to be effective, she thought, since she then managed to get to sleep. She only noticed her mistake the next day. Convinced that this medicine contained a molecule that helped her to relax, she continued taking it for this purpose during the periods she experienced difficulties in getting to sleep.

Discovering a mistake, even when an improvement has occurred, does not however always lead to reuse of the medicine in question. One evening, $\mathrm{Mr} \mathrm{H}$, who suffered from muscular pain in his arm, coated the muscle in an antihistaminic cream (that he had once bought to treat mosquito bites), thinking he was using an anti-inflammatory cream. The following day, when his muscle appeared to be hurting less, he noticed his mistake. He concluded that the cream he had used the day before had had a placebo effect, since when he thought it was appropriate for his pain, it had relieved it. Nevertheless, he regrets that it can no longer work on him since he is now aware that using it is inappropriate and the trickery he had involuntarily exposed himself to cannot be repeated.

And finally, a placebo can be used in order to ensure that the symptom the subject is complaining of is indeed serious. This is particularly the case for children and elderly people. When her children complain of pain, Mrs L experiments with the use of what she considers to be placebos and then if the pains go away or diminish, she judges them to be not serious or even devoid of pathological character. This can be called the diagnostic use of the placebo.

However, research into the domestic uses of medicines reveals that more complex situations exist, where the substance used takes on an ambivalent or different status depending on the person. This is the case for homeopathy, which some people buy without believing in the existence of any active ingredient, but from which they expect a placebo effect on their child. Some people choose to resort to a product to which they assign exclusively placebo properties, in the manner of the rheumatologist with the anti-arthritics mentioned above, while others credit the product with an intrinsic efficacy. One man who was worried about his mother regularly taking Seresta (an anxiolytic of the benzodiazepine family) to get to sleep, bought her Cocculine (a homeopathic medicine sold for travel sickness) even though he was convinced that homeopathy had no innate efficacy - because he thought these homeopathic granules looked like the Seresta pills. This phenomenon can also be observed amongst pharmacists, whose practices it is worth 
examining since recourse to placebos in family medicine is sometimes carried out with the complicity of health professionals, whether they actually make a 'pure' placebo or provide advice on an 'impure' one.

\section{Placebos in officinal practice}

The interviews carried out with pharmacists concerning their experience on the subject reveal some contrasting perceptions of what a placebo is. Some occasionally make and dispense true placebos:

It can happen that I give a placebo. Around ten or fifteen years ago, I had a patient who was taking Tranxene 10; it was a young 19-year-old man. His father was very worried about it and he wanted his son to get out of the habit. 'It's in his head,' he told me. He asked me to take the tablets and put something else inside. I thought of putting lactose in, but I asked his GP anyway. 'Why not?', he said to me, 'we can try it'. It's true he was taking it out of habit. We gave him lactose for several months and he ended up stopping, I suppose, because I still see him, but without a Tranxene prescription. (PZ, $\left.\mathrm{ph}^{5}\right)$

There are clients who ask me for something harmless for family members. Especially for sleeping problems, to avoid taking anxiolytics. One day, I made one up especially for a client. I made placebo capsules with starch and sugar; and then he asked for more because it had worked. But it's not easy because they have to look like the capsules or pills that the patient normally takes. They have to anyway, for the placebo effect to work! (FB, ph)

Questions about the use of placebos invariably lead pharmacists to bring up homeopathy. The extracts of interviews that follow (carried out with ten pharmacists from different towns in France) show that homeopathy is considered as a placebo by some and as a true, but harmless, medicine by others. Qualifying it as a placebo is subjective, and pertains to a non-shared cognitive system. Thus, among the pharmacists who were asked if any clients ever request placebos, or if they ever use or advise placebos, they all ended up mentioning homeopathy, either (more often) to associate the two, if they refute any intrinsic efficacy in the product, or to the contrary, to disassociate them, if they believe the granules do carry a certain efficacy ${ }^{6}$. In all cases, the use is linked to the wish to satisfy clients who want to avoid the risks associated with consuming certain medicines. 
If they ask me, I sometimes give something mild, homeopathy for example, it's not bad, it can't do any harm. We have no proof that it is effective so it is a bit of a placebo. For example, I give homeopathy for a child whose ears hurt when on an aeroplane. Anyhow, sucking on granules makes them swallow, so it will unblock their ears; this can also be done with a sweet, but these pills make it seem more serious. (OD, ph)

In other cases, a placebo is not asked for explicitly, but the pharmacist perceives the request to be implicit.

When a mother asks me for something to calm her child, she wants something mild, with no side effects. So I propose homeopathy. To me, it is a placebo. To the patients, it is not an explicit request for a placebo, it is there but hidden. She might say to me for example: 'If he has his three granules, he stops crying! (SE, ph)

Sometimes the patients ask me for something gentle for a family member; well it's a bit like asking for a placebo, even if they don't say it openly. For example, a mother who asks for something for her child who is stressed about school. The most important thing is that it is not harmful, so as to not feel guilty; it takes the blame away from her, because if she gives her son something with side-effects, she feels guilty. And so we use homeopathy, because there, there is no impact on the physiology of the organism. (AL, ph)

If they ask me for something harmless for a family member to avoid giving him/ her anxiolytics, we can also give them homeopathy. For the patients to trust it and for it to work, I tell them: 'don't take more than so many per day'; when in fact, they can take as many as they like! It's true that it prevents any side effects for elderly people because hypnotics can lead to memory loss! There is a lot of talk about Alzheimer's, and with all these excessive prescriptions of psychoactive drugs, people are scared! Personally, I am pretty rational; homeopathy is not proven. Of course, we can't treat everything with homeopathy, because we can't treat everything with placebos! (FB, ph)

This position resonates with the works of authors such as Jonas, Katchup \& Linde (2003), who stressed that double blind randomised clinical trials against placebos showed that for some afflictions there was no difference between the results obtained by placebo and by homeopathy, and they conclude that a large majority of the therapeutic effects of homeopathy rely on the placebo effect. 
But not all pharmacists believe homeopathy is a placebo. Mrs B is trained in homeopathy and displays her qualification certificate in her pharmacy. She said:

I have never been asked for a placebo. Sometimes they want something extra, they ask for homeopathy for example because they are less afraid of it, because there are no adverse side effects. I only give them this if they ask for it as an extra, not to replace a prescribed medicine. But I always give them something real; never a placebo. Something like homeopathy or herbal medicine. (Mrs B, ph)

They never ask me for placebos and I never give them. I sometimes give something with no adverse side effects, for example sea water instead of nose drops, or herbal teas rather than antibiotics, for example for cystitis. They are not placebos since there is still a mechanical action. Or also homeopathy, but I never give placebos. (RM, ph)

The idea that homeopathic medicine has an active principle or a 'mechanical action' is based on the underlying belief system according to which the active principle of the substance (vegetable, animal or mineral) used still works, even though it is highly diluted, since homeopathy is based on the principle of similarity, the theory that a substance with a certain effect would have the inverse effect when heavily diluted.

We can note here that, among the pharmacists who say they suggest their clients take homeopathy, some do so to illustrate their use of placebos, while other to prove that, in response to patient requests for 'something mild', they always prescribe 'real medicines'. Consequently, when questioned about their uses of placebos, some mention homeopathy to answer in the affirmative, while others do so to respond in the negative.

\section{The actors' ethical positions}

As opposed to 'impure' placebos that do possess an active principle but are indicated for other pathologies, Lemoine (1996) thinks that 'the pure placebo is a pure lie' (p.35). The different positions on the ethical dimension of this matter highlight attitudes that are subject to moral judgements. Is it ethical to prescribe placebo drugs for therapeutic ends? The ethical question is generally raised in reference to 'pure' placebos. However, it can also be applied to the prescription of impure 
placebos if the person who prescribes or advises them is convinced they will be ineffective in the situation in question.

The social actors (users and pharmacists) never mention the subject of placebos without linking their words and observations concerning their uses to ethical considerations. Their arguments to justify their use, or refusal, of placebos mobilise ethical or therapeutic reasons in unequal proportions that vary depending on the individuals. And the alchemy between these two types of reasons forms the basis for how they choose to act.

Some pharmacists believe using placebos is perfectly ethical in that they judge the desired (therapeutic) effect to be beneficial to the patient. Various studies have shown that doctors sometimes deem recourse to placebos to be ethical ${ }^{7}$, and we can see that these pharmacists have developed analogous postures. Others, on the other hand, condemn this use, also for ethical reasons. Among the stances that are ethically against the use of placebos, we find the argument that administering a placebo risks damaging the relationship of trust between patient and health professional if the patient discovers the truth. For this same reason, Bok (1999) condemns the use of placebos as a deceptive practice and underlines the risk of eroding patient trust - a trust that is indispensable in all health care relationships.

Another reason for disagreeing with the practice is that the use of a placebo is a way of discrediting the person's complaint. This position is supported by the American Pain Society who oppose the use of placebos to alleviate pain in clinical practice partly because, according to the bioethical law, patients should be informed and should give their consent for all medical treatment and partly because the analgesic effect of a placebo does not provide useful information on the origin and severity of the pain, and that the deceptive use of placebos is a means of discrediting the patients' perceptions of pain (Sullivan et al., 2005).

Some pharmacists express rather extreme ethical reservations:

I have never given a placebo to a patient, I find that shocking! I have never made any and would refuse if I was asked. That would be like a mechanic hitting the bonnet three times with a hammer instead of repairing your car! (SR, ph)

I have an ethical position on that: no placebos! (LE, ph)

But they can also be more moderate:

I agree with using placebos if the case is well understood. Sometimes, I sell them to clients who ask for a little something for their mother, but only if the patients are 
being monitored by a doctor. There, we can use a placebo. We have to ensure we are not putting the person in danger. If the treatment is being closely checked by the children (or someone who is physically and psychologically close to the patient), placebos can be given at home, in addition to corticoids for example. When the request comes from the family, and the patient is already taking a large amount of medicines and they want to ease and reduce this medication load (for example to avoid pharmaceutical hepatitis from excessive doses of paracetamol); well, in that case, why not use a placebo? (JLF, ph)

The position is more ambiguous when the disassociation between placebos and homeopathy is based on a legislative framework and reluctance to give placebos is expressed in terms of the legal context:

I never give placebos. There is a degree of 'psychological manipulation' that I don't like. I sometimes give homeopathy; that is acceptable, but not placebos. Anyway, the law prohibits it. (RM, ph)

In any case, homeopathy is our only option. We can't advise a true placebo, because if they found out, we would be in trouble! (AL, ph).

To understand the meaning and ramifications of these diverse positions, they should be put in perspective with the legal context in which the placebo is conceptualised in France. Yet, as Guimet (2012) notes, no recommendations exist for clinical practice on the use of placebos in France, even though the placebo effect and placebo medicines in medical practice are explicitly mentioned in the medical curriculum (see: Scientific Council of Medicine, Pedagogic objectives of the 2nd cycle of medical studies (years 4-6), updated in June 2011). However, the use of placebos can only be considered compatible with the French legislation if it is undertaken with the patient's informed consent, as stipulated in the French patient rights law of 4 th March 2002. This law stipulates that in the light of information and advice supplied by healthcare professionals and in consultation with them, all patients are entitled to take decisions regarding their own health, and specifies that the information should notably include the treatments proposed and their utility. We can see that the way this law is interpreted leads some to believe the deceptive use of placebos to be inadmissible (in that it does not respect the principle of patient autonomy), while it leads others to justify the practice based on the idea that placebos can be useful in improving patient health. This ambiguity can be found in the definition of a medicine by the Public Health Code (Code de la Santé Pub- 
lique): 'Any substance or combination of substances presented as [my italics] possessing curative or preventative properties for human beings or animals... in view of restoring, correcting or modifying their physiological functions..', and is also present in the writings of the French National Medical Council (Ordre National des Médecins) (2012): 'In medical practice, the placebo effect is a therapeutic means that should not be neglected but ethical behaviour is required in using it in order for the ritual of the consultation to reach its term. The doctor, in prescribing a placebo, wants to please or does so to avoid a useless prescription [my italics]. The doctor-patient relationship adds value to the prescription of a placebo' (p. 28). On the other hand, because homeopathic medicines have a Marketing Authorisation, they do not raise such ethical dilemmas for pharmacists, even when these latter consider them to be equivalent to placebos.

\section{Discussion}

As we have seen, the use of placebos for therapeutic reasons (in other words, the quest for efficacy with the least iatrogenic risk $)^{8}$ sometimes comes up against a refusal of placebos for ethical reasons. For some, the ethical position on the subject consists of thinking that the only situation in which it is legitimate to prescribe a placebo medicine would be when no known active treatment is available, either because it allows results to be obtained, or for the psychological wellbeing of the patients (to comfort them). This position can also be found amongst users: Mrs S, a retired 75-year-old secretary, is in favour of the prescription of placebos. She assumes that her father, who was suffering from cancer and has since died, received placebos from his doctor. She is happy about this because she thinks that it comforted him and that, 'in any case, there was nothing that could cure his problem at that time'.

The debate on whether using placebos is ethical or not relates to the question of their social acceptability. It is noticeable that the positions are based on different values and stakes, some in line with the principle, others with the result. The position based on the principle consists of believing that placebos should never be used except in therapeutic trials, out of respect for the patient. Whereas the position based on the result says that there is no deception on the product and its claimed efficacy if the patient experiences an improvement because he/she believes he/she will get better, in other words, if there are results. Skrabanek and McCormick (1998) go as far as asking: 'why is it a deception to administer a pla- 
cebo when the large majority of current therapeutics do not give better results?' (p. 14). Here, the judgement is based on the benefits. The ethics is not based on principle but on pragmatism, depending on its utility. Thus there exist two main attitudes to placebos that emerge from the actors' perceptions; that of the 'principlists' as opposed to the 'utilitarianists'. In this latter category we find those who, like LE (ph), believe:

We should encourage people not to accustom their children to solving their problems with medication, and we should propose homeopathy for example. Then, even if there is no effect, it is not a placebo (LE, ph).

This position is disputed by those who think using placebos risks, in contrast, reinforcing the patient's belief that recourse to medication is obligatory when in fact looking for a psychotherapeutic treatment or improving one's lifestyle (sleeping hours, work organisation, nutrition) would be better alternatives.

It is interesting to note that the notion of ethical risk disappears when homeopathy is used, even when the pharmacist is convinced that there is no active principle in these substances. This leads us to note that the question cannot be reduced to one of being either for or against the use of placebos, and that it must be addressed in a much more complex way to the extent that not only does the evaluation of the ethical nature of the use of placebos depend on the context in which it is applied, but that the very definition of what a placebo is varies according to the individuals' cognitive system. In a more moderate manner, some professionals who support the use of placebos think that such prescriptions are ethical when one is aiming to act on the symptoms but not when one is claiming to act on the illness itself.

Diverse attitudes can also be observed among the patients or users. Some would like to be able to be fooled with placebos in order to manage their affliction and to recover with the least possible physiological costs, that is to say without poisoning themselves or without experiencing the negative effects of real medicines, while others are very resistant to the idea that they could be deceived, saying they want to keep perfect control of their bodies and thus they denounce, on principle, the deception they would be subject to. Others again are totally against it for themselves but not for their relatives. The patients' attitudes to placebos partly echo the pharmacists' positions on the ethical or non-ethical nature of their use, insofar as they give rise to the construction of differing value systems, some in line with the principle, others with the result. 


\section{Conclusion}

The material gathered enables me to propose several conclusions:

1) As regards the 'placebo effect' with officinal advice, there is, in addition to the 'doctor effect', what can be called the 'pharmacist effect' since it is the pharmacist who dispenses the product, beyond even the medical prescription - whether it is a case of advising 'impure' placebos, suggesting homeopathic granules, or making 'pure' placebos. But to these effects we should add a 'trusted person effect', since family medication can take place outside the pharmacist-user relationship and this effect can result from trust put in a family member or close friend ${ }^{9}$, or from the patients' conviction in the competence of the person advising them.

2) If choosing a placebo is a means of avoiding certain medicines or the risks associated with them (such as antibiotics, anti-inflammatories and psychoactive drugs), it is also a means of medicalizing a problem without pharmaceuticalizing it.

3) Beyond the distinction between 'pure' and 'impure', there exist situations where people use placebos that could be called 'of the third type' since their status varies depending on the actors. This is the case for homeopathy and anti-arthritics for example, as we have seen above.

4) Although some pharmacists and users qualify homeopathy as a placebo or a substance that produces a placebo effect, the ethical question does not appear to trouble them when using homeopathic medicines, even when the pharmacist uses them solely for their virtues as a placebo. The legal status of homeopathy as a 'medicine' exempts the pharmacist from ethical questioning even when he/she believes it to be a placebo, and lets the clients believe that it is a medicine endowed with an efficacy equivalent to allopathic medicines, with the only difference being the absence of adverse side-effects. Thus, using homeopathy does not pose ethical problems to those very people who believe it is totally devoid of efficacy when such questions would be raised for any official placebo. The legal recognition of homeopathy in France allows pharmacists to exonerate themselves from a professional practice they would otherwise judge to be non-ethical. The relationship between therapeutic choice and ethical choice is formed around the ambiguous and variable status of the concept of placebo. 
Alongside the strictly technical aspect of the placebo, is the socially constructed perception of medicine and efficacy that is contained within the concept of placebo. This concept is used by the actors to evaluate, measure or signify efficacy; it can be applied to a medicine by some to disqualify it and by others to legitimise it. As we can see, the starkly contrasting positions which form the basis of the choice to use a placebo or not, result from an alchemy of two concerns: the management of therapeutic risks and the management of ethical ones.

\section{Acknowledgments}

This study, carried out within the framework of research on Lay Perception and Management of Drug Risk, is supported by the ANSM (National Agency for Drug and Health Product Safety).

\section{Notes}

1: The distinction between the placebo and placebo effect is as follows: the placebo is a substance with no pharmacological effect, a pharmacologically inert substance given in a therapeutic context; the placebo effect however describes the difference between the expected therapeutic effect and the observed therapeutic effect. In this regard, the placebo effect - which Moerman (2000) calls 'the meaning response' (p.56) - can describe any effect that can be attributed to a medicine, but also to an exploration, act or action that is independent from its specific or pharmacological properties (cf. Price, Finiss \& Benedetti, 2008).

2: This aspect has been thoroughly investigated in psychology (Zigmond, 1984; Kirsch, 2011) and in social psychology (Balez, Leroyer \& Couturaud, 2014) where the relational aspects of medical practice have been underlined.

3: $12 \%$ of respondents used pure placebos while $97 \%$ used impure placebos at least once in their career. $1 \%$ of respondents used pure placebos, and $77 \%$ used impure placebos at least once per week.

4: It should be noted that the belief that paracetamol is a benign product is common amongst French users.

5: The letters, 'ph', that appear in parentheses after the fictitious initials of the speakers are used to show they are dispensary pharmacists.

6: Evidently, in no way should anthropologists take a personal position on homeopathy, nor should we voice any opinions on the validity of its use, but we can examine the uses and discourses concerning homeopathy in terms of the link to the issue of placebos.

7: In the study reported by Howick et al., (2013), most respondents stated placebos (66\% for pure, $84 \%$ for impure) were ethical in some circumstances. Equally, according to 
Tilburt et al. (2008), most doctors consider the use of placebos to be an ethical practice or at least ethically admissible.

8: A lesser but never zero risk since the nocebo effect can sometimes occur.

9: This relationship of trust is not reduced to intra-family relationships, and can be widened to the friendship network.

\section{References}

Aulas, J.J. (2008). Placebo et effet placebo dans l'histoire de la médecine. In P. Maire \& R. Boussageon (Eds.), Placebo, le remède des remèdes (pp. 23-34). Lyon : Jacques André éditeur.

Balez, R., Leroyer, C. \& Couturaud F. (2014). Effet placebo : un regard de psychologie sociale. Revue des maladies Respiratoires, online [http://www.sciencedirect. com/science/article/pii/S0761842514001053], accessed 02/07/2014.

Balint, M. (1957). The Doctor, his Patient and the Illness. London: Pitman.

Beecher, H. (1955). The powerful placebo. Journal of the American Medical Association, 159, 1602-1606.

Benedetti, F., Mayberg, H.S., Wager, T.D., Stohler, C.S., Zubieta, J.-K. (2005). Neurobiological Mechanisms of the Placebo Effect. The Journal of Neuroscience, 25, 45, 10390-10402.

Benedetti, F., Amanzio, M. (2011). The placebo response: how words and rituals change the patient's brain. Patient Education and Counseling, 84, 3, 413-9.

Bok, S. (1999). Lying: moral choice in public and private life. New York: Vintage books. Boussageon, R. (2008). L'effet placebo : Le 'côté obscur' de l'essai clinique contrôlé. In P. Maire \& R. Boussageon (Eds.), Placebo, le remède des remèdes (pp. 107-134). Lyon: Jacques André éditeur.

Brody, H. (1997). The Doctor as Therapeutic Agent: A placebo effect research agenda. In A. Harrington (Ed.), The Placebo Effect: An Interdisciplinary Exploration (pp. 77-92). Cambridge, MA: Harvard University Press.

Cathebras, P. (2006). Troubles fonctionnels et somatisation. Comment aborder les symptômes médicalement inexpliqués. Paris: Masson.

Cathebras, P. (2008). La prière et la médecine fondée sur les preuves : où se situe le religieux? In P. Maire \& R. Boussageon (Eds.), Placebo, le remède des remèdes (pp. 185-196). Lyon : Jacques André éditeur.

Fainzang, S. (2001). Médicaments et société. Le patient, le médecin et l'ordonnance. Paris: Presses Universitaires de France. 
Fainzang, S. (2005). Religious Attitudes toward Prescriptions, Medicines and Doctors in France, Culture, Medicine and Psychiatry, 29, 4, 457-476.

Fainzang, S. (2012). L'automédication ou les mirages de l'autonomie. Paris: Presses Universitaires de France.

Fainzang, S. (2013). The Other Side of Medicalization: Self-Medicalization and Self-Medication, Culture, Medicine, and Psychiatry, 37, 3, 488-504.

Fainzang, S. (2014). Managing Medicinal Risks in Self-Medication, Drug Safety, 37, 5, 333-342.

Guimet, P. (2012). L'usage de placebos en médecine générale. Enquête auprès de médecins généralistes français. HAL Id: hal-00663369 [https://hal.archivesouvertes.fr/hal-00663369], accessed 12/01/2015.

Helman, C.G. (2001). Placebos and nocebos: the cultural construction of belief. In D. Peters (Ed.), Understanding the Placebo Effect in Complementary Medicine: Theory, Practice and Research (pp. 3-16). London: Churchill Livingstone.

Hofling, C. K. (1955). The place of placebos in medical practice. Gen. Practice (Kansas City), 11, 103-107.

Howick, J., Bishop, F.L., Heneghan, C., Wolstenholme, J., Stevens, S., Hobbs, F.D.R., Lewith, G. (2013). Placebo Use in the United Kingdom: Results from a National Survey of Primary Care Practitioners. PLoS One, 8, 3, e58247.

Jensen, K., Kaptchuk, T.J., Chen, X., Kirsch, I, Ingvar, M., Gollub, R.L., Kong, J. (2014). A neural mechanism for nonconscious activation of conditioned placebo and nocebo responses. Cerebral Cortex, 1-8.

Jonas, W.B., Kaptchup T.J., Linde, K. (2003). A critical review of homeopathy. Ann Intern Med, 138, 393-459.

Lemoine, P. (1996). Le mystère du placebo. Paris: Éditions Odile Jacob.

L'Express (2012). Les médecins demandent des examens supplémentaires pour se couvrir [http://www.lexpress.fr/actualite/societe/sante/les-medecins-demandent-des-examens-supplementaires-pour-se-couvrir_1134364. html\#Kwd5qwqtrb5VwPpA.99], accessed 4/07/2014.

Maire, P. (2008). Le remède des remèdes. In P. Maire \& R. Boussageon (Eds.), Placebo, le remède des remèdes (pp. 35-50). Lyon : Jacques André éditeur.

Mayberg, H.S., Silva, J.A., Brannan, S.K., Tekell, J.L., Mahurin, R.K., McGinnis, S., Jerabek, P.A. (2002). The Functional Neuroanatomy of the Placebo Effect. Am J Psychiatry, 159, 728-737.

Moerman, D. (2000). Cultural Variations in the Placebo Effect: Ulcers, Anxiety, and Blood Pressure. $M A Q, 14,1,51-72$ 
Moreau, A. (2008). L'«effet médecin« à l'heure de l’EBM. In P. Maire \& R. Boussageon (Eds.), Placebo, le remède des remèdes (pp. 81-87). Lyon: Jacques André éditeur.

Ordre National des Médecins (2012) La prescription et la place du médicament dans la relation Médecin-Patient-Pharmacien. Aspects réglementaires, éthiques et déontologiques. Commission nationale permanente.

Ostenfeld-Rosenthal, A. (2012). Energy healing and the placebo effect. An anthropological perspective on the placebo effect. Anthropology \& Medicine. 19, 3, 327338.

Peters, D. (Ed.) (2001). Understanding the Placebo Effect in Complementary Medicine: Theory, Practice and Research. London: Churchill Livingstone.

Pignarre, P. (2008). La cause placebo. In P. Maire \& R. Boussageon (Eds.), Placebo, le remède des remèdes (pp. 89-100). Lyon : Jacques André éditeur.

Price, D.D., Finniss, D.G., Benedetti, F. (2008). A Comprehensive Review of the Placebo Effect: Recent Advances and Current Thought. Annu. Rev. Psychol., 59, 565-90.

Spiro, H. M. (1986). Doctors, Patients and Placebos. New Haven: Yale Univ. Press. Skrabanek P, \& McCormick J. (1998). Follies and fallacies in medicine. Chippenham. Tarragon Press.

Sullivan, M., G., Terman, W., Peck, B., Correll, D.J., Ben Rich, JD, Clark, W. C., Latta, K., Lebovits, A., \& Gebhart, G. (2005). APS Position statement on the use of placebos in Pain management, The Journal of Pain, 6, 4, 215-217.

Thalabard, J.C. (2008). Le placebo : un concept nécessaire ? In P. Maire \& R. Boussageon (Eds.), Placebo, le remède des remèdes (pp. 135-141). Lyon : Jacques André éditeur.

Thompson, J.J., Ritenbaugh C. \& Nichter M. (2009). Reconsidering the Placebo Response from a broad Anthropological Perspective. Culture, Med and Psychiatry, $33,1,112-52$.

Tilburt, J. C., Emanuel, E. J, Kaptchuk, T. J., Curlin, F. A., \& Miller, F. G. (2008). Prescribing "placebo treatments": results of national survey of US internists and rheumatologists. BMJ, 337, a1938.

Vega, A. (2011). Cuisine et dépendance : les usages socioculturels du médicament chez les médecins généralistes français. Final report, [http://www.formindep. org/IMG/pdf/rapport_final3.pdf], accessed 15/05/2014.

Whyte, S. R., Van der Geest, S. \& Hardon, A. (2002) Social lives of medicines. Cambridge: Cambridge University Press. 
Zigmond, D. (1984). Mother, Magic or Medicine? The Psychology of the Placebo. British Journal of Holistic Medicine [http://www.marco-learningsystems.com/pages/david-zigmond/v3-mother-magic.htm], accessed 27/06/2014. 